\title{
VU-Serviços para universitários
}

\section{Efraim S. Leite Filho ${ }^{1}$, João O. Bovoloni Falavigna ${ }^{1}$, Adriano S. De Lima ${ }^{1}$}

${ }^{1}$ Universidade Tiradentes (UNIT) - Aracaju, SE - Brasil

efraimleite@gmail.com, joaootaviobf21@gmail.com, adrianoslegmail.com

ABSTRACT Due to the difficulties faced by undergraduate students, the "Via Universitária" is a platform seeking to make their day to day lives easier, offering 4 core services: Rooms for rental, classes schedule, events available nearby and carpool rides.

RESUMO Em razão dos obstáculos enfrentados pelos estudantes universitários, o Via Universitária é uma plataforma que visa facilitar a rotina do dia a dia, oferecendo 4 serviços: Acomodações para alugar ou dividir, procurar aulas de interesse, sugestão de eventos próximos e caronas.

\section{Introdução}

Segundo o censo da educação, ensino superior tem 8,05 milhões de alunos matriculados em 2016. E dados do IBGE afirmam que 29,2\% dos alunos que cursam o nível superior estudam em uma cidade diferente da que vive. A tendência é que esse número cresça cada vez mais e gere uma demanda no mercado que vise facilitar a vida dos universitários. Dentre as dificuldades enfrentadas pelos universitários a moradia é uma das principais, tendo vista que o custo de se deslocar até a cidade de estudo para procurar um quarto antes de iniciar o período das aulas e o entrave de encontrar um local disponível que esteja perto da faculdade ou até mesmo de encontrar outros universitários que possam dividir os custos. Além da moradia, há outros gastos, como alimentação, entrada para congressos e eventos e materiais de estudos. Muitos dos alunos recorrem a oferecer aulas e cursos para outros estudantes, como forma de ganhar alguma renda. Por fim, o deslocamento também compromete o financeiro dessas pessoas, forçando-as a recorrer a transportes públicos ou aplicativos como o Uber. O Via Universitária tem o objetivo de ser uma plataforma para unir alunos em busca destes serviços e pessoas como quartos disponíveis, caronas, como também servir de intermediário entre alunos que oferecem aulas e cursos e estudantes que as procuram.

\section{Descrição do Aplicativo e Contribuição Tecnológica}


Visando ajudar os universitários foi criado o aplicativo Via Universitária, com 4 funções diferentes: Apartamentos,aulas, eventos, caronas. $\mathrm{Na}$ função apartamentos o universitário irá consultar em um mapa com um campo de busca, apartamentos que estejam disponíveis tanto para aluguel quanto para dividir .Na função aulas o universitário irá consultar em um mapa com um campo de busca, aulas que sejam do seu interesse. $\mathrm{Na}$ função eventos o universitário irá consultar em um mapa com um campo de busca, eventos que estejam ocorrendo na cidade, desde festas até palestras.Na função carona o usuário poderá tanto pedir carona quanto oferecer. Ao oferecer uma carona o app irá verificar quais pessoas estão indo para a mesma faculdade e no mesmo trajeto. E ao solicitar uma carona o usuário irá esperar que alguém que possa oferecê-la.Os cadastros de apartamentos, aulas e eventos será feito pelo próprio usuário. Além disso, o app também conta com a função de chat e comentários.

\section{Conclusão e Perspectivas Futuras}

A adaptação sempre estará presente na vida de um acadêmico, isso irá fazer parte desde o início da graduação até a conclusão do curso, e dessa forma sempre vai vir o aprendizado. Contudo existem meios de tecnologias e inovações, que torna esse caminho mais fácil, esse é o foco da via universitária, ajudar o acadêmico a suprir suas necessidades tornando a graduação menos desgastante.

\section{Referências}

IBGE: No nível superior, 29\% dos alunos saem de sua cidade para estudar", http://www.planalto.gov.br/ccivil_03/_ato2011-2014/2011/lei/112527.htm; Acesso em: 05/05/2019.

Ensino superior tem 8,05 milhões de alunos matriculados em 2016", http://www.brasil.gov.br/noticias/educacao-e-ciencia/2017/08/ensino-superior-tem-8-05milhoes-de-alunos-matriculados-em-2016; Acesso em: 02/05/2019. 